\title{
Characteristics of corneal high-order aberrations in adolescents with mild to moderate myopia
}

\author{
Xu Zhang ${ }^{1 \dagger}$, Jin-Hui $\mathrm{Ma}^{2+}, \mathrm{Xin}_{\mathrm{X}}^{3^{*}}$ and Lin Guan ${ }^{4}$
}

\begin{abstract}
Background: This study investigated the characteristics of corneal higher-order aberrations (HOAs) of the anterior surface, posterior surface, and total cornea in adolescents with mild to moderate myopia.

Methods: A total of 183 patients with myopia (183 eyes) aged 8 to 18 years were enrolled in this study. The axial length (AL) of the eyes was measured by an IOL-Master, and corneal curvatures (K-values) and HOAs were measured by a Pentacam anterior segment diagnostic analyzer.

Results: Results of this study showed that the anterior, posterior and total corneal horizontal coma $Z_{3}{ }^{1}$ were $-0.1249 \pm$ $0.105 \mu \mathrm{m}, 0.0009 \pm 0.001 \mu \mathrm{m}$, and $-0.1331 \pm 0.116 \mu \mathrm{m}$, respectively; the anterior, posterior and total corneal vertical coma $Z_{3}{ }^{-1}$ were $-0.0212 \pm 0.164 \mu \mathrm{m}, 0.0003 \pm 0.043 \mu \mathrm{m}$, and $-0.0216 \pm 0.168 \mu \mathrm{m}$, respectively; and spherical aberration (SA) $Z_{4}{ }^{0}$ values were $0.2244 \pm 0.091 \mu \mathrm{m}, 0.1437 \pm 0.029 \mathrm{um}$, and $0.1889 \pm 0.090 \mu \mathrm{m}$, respectively. Total corneal $Z_{3}{ }^{1}$ was statistically correlated with posterior corneal astigmatism $\left(K_{2} b-K_{1} b\right)(p=0.038)$. Total corneal $Z_{3}{ }^{-1}$ was correlated with anterior corneal astigmatism $\left(K_{2} f-K_{1} f\right)(p=0.027)$. Anterior, posterior, and total corneal $Z_{4}^{0}$ were correlated with anterior and posterior corneal curvature $\left(K_{1} f, K_{2} f, K_{1} b, K_{2} b\right)(p=0.001)$. Posterior corneal $Z_{4}{ }^{\circ} b$ was also significantly correlated with $A L$.

Conclusions: In adolescents with mild to moderate myopia, the posterior corneal surface shape may play a compensatory role in the balance of corneal aberrations, and the posterior corneal SA tended to become less negative as the AL increased. The corneal coma may also play a compensatory role in posterior corneal surface astigmatism, which was valuable for the treatment for improving visual quality. This conclusion still needs to be verified.
\end{abstract}

Keywords: Corneal high-order aberration, Myopia, Ocular axial length, Corneal curvatures, Orthokeratology

\section{Background}

The prevalence of myopia is high in East Asia, and approximately one in six of the world's population is myopic [1, 2]. The prevention and control of adolescent myopia are of global importance because of its high burden on vision health. Some scholars believe that the decline in retinal imaging quality caused by high-order aberrations (HOAs) may be a factor that influences the development of myopia

\footnotetext{
*Correspondence: ywdr_mnql123@163.com

${ }^{+}$Xu Zhang and Jin-Hui Ma contributed equally to this work.

${ }^{3}$ Central Laboratory, Affiliated Hospital of Hebei University, No 212.

Yuhuadong Road, Lianchi District, Baoding 071000, China

Full list of author information is available at the end of the article
}

in children [3-7]. In a study conducted by Zhang et al., HOA without spherical aberration (SA) was correlated with the progression of myopia [4], and it was predicted that HOA is a risk factor for myopia progression. Animal studies showed that a form of deprivation or lens-induced blur can induce myopia by degrading the quality of the retinal image [5]. Wang et al. [6] suggested that HOAs may be a cause of accommodative anomalies, while Kirwan et al. [7] found that myopic eyes have more HOAs than emmetropic eyes. However, Cheng et al. [8] found no correlation between refractive error diopter and either SA or HOAs.

C C The Author(s). 2020 Open Access This article is licensed under a Creative Commons Attribution 4.0 International License, which permits use, sharing, adaptation, distribution and reproduction in any medium or format, as long as you give appropriate credit to the original author(s) and the source, provide a link to the Creative Commons licence, and indicate if changes were made. The images or other third party material in this article are included in the article's Creative Commons licence, unless indicated otherwise in a credit line to the material. If material is not included in the article's Creative Commons licence and your intended use is not permitted by statutory regulation or exceeds the permitted use, you will need to obtain permission directly from the copyright holder. To view a copy of this licence, visit http://creativecommons.org/licenses/by/4.0/ The Creative Commons Public Domain Dedication waiver (http://creativecommons.org/publicdomain/zero/1.0/) applies to the data made available in this article, unless otherwise stated in a credit line to the data. 
Hiraoka et al. [9] found significant increases in corneal and total ocular HOAs after orthokeratology.

Most of the previous studies of HOAs only focus on myopia in adults. The aberrations of human eyes mainly come from corneal aberrations, which are closely related to the visual quality of the human eyes $[10,11]$. Therefore, we conducted this study to investigate the characteristics of corneal HOAs of the anterior surface, posterior surface and total cornea in adolescents with mild to moderate myopic eyes.

\section{Methods}

\section{Patients}

In this study, adolescent myopia patients in Baoding Yinghua Eye Hospital, Baoding City, Hebei Province, China, were recruited between January 2016 and May 2018. This research adhered to the principles highlighted in the Declaration of Helsinki and was approved by the Institutional Review Board of Clinical College of Ophthalmology in Tianjin Medical University. Informed consent was obtained from each participant.

\section{The inclusion and exclusion criteria}

The inclusion criteria were: (1) patients with myopic eyes and best corrected visual acuity above 1.0 without other ocular disease; (2) patients aged between 8 and 18 years; (3) intraocular pressure (IOP) $<21 \mathrm{mmHg}$; (4) in order to avoid the correlation of binocular growth and the influence of aberrations directionality, all the patients were enrolled in the right eye group.

The exclusion criteria were: (1) patients with a congenital cataract, corneal disease, uveitis, fundus disease, and other eye diseases; (2) patients who had undergone previous intraocular surgery; (3) patients aged less than 8 or more than 18 years; (4) intraocular pressure (IOP) $\geq 21 \mathrm{mmHg}$.

\section{Ocular examinations}

The diopter was determined utilizing the cyclopentanone mydriasis and atropine amide mydriasis assays for children aged $\leq 10$ and $>10$ years, respectively. The axial length (AL) measurements were taken five times using an intraocular lens biometric instrument (IOL-Master 2.0, Zeiss, Germany), and the values were averaged. Moreover, corneal curvature and aberrations were measured with the patient in the sitting position, with the patients' natural pupil size, and in a dark environment. An anterior segment analyzer (Pentacam 70,700, Oculus, Germany) was utilized. The Pentacam anterior segment analysis system provides a $360^{\circ}$ uniform rotation scanning technique based on the Scheimpflug principle, which is a reliable technique for measuring anterior, posterior, and total corneal aberrations.

After recording the patients' information, the researchers instructed them to place their lower jaw on the lower jaw rest and their forehead against the forehead rest.
The patients' eyes were then kept wide open, and the patient was instructed to look at the flashing blue lights. The inspector utilized the operating rod according to the screen prompt direction focus. K1 referred to minimum corneal curvature, and $\mathrm{K} 2$ referred to maximum corneal curvature. After adjusting the alignment, 25 frames of the Scheimpflug images were utilized to reconstruct the three-dimensional structure of the anterior segment and measure the curvature of the anterior $\left(\mathrm{K}_{1} \mathrm{f}\right.$ and $\left.\mathrm{K}_{2} \mathrm{f}\right)$ and posterior $\left(K_{1} b\right.$ and $\left.K_{2} b\right)$ surfaces of the cornea. Zernike was utilized for analyzing the anterior corneal surface $\left(\mathrm{Z}_{3}{ }^{1} \mathrm{f}, \mathrm{Z}_{3}{ }^{-1} \mathrm{f}\right.$, and $\left.\mathrm{Z}_{4}{ }^{0} \mathrm{f}\right)$, the posterior corneal surface $\left(\mathrm{Z}_{3}{ }^{1} \mathrm{~b}\right.$, $\mathrm{Z}_{3}{ }^{-1} \mathrm{~b}$, and $\left.\mathrm{Z}_{4}{ }^{0} \mathrm{~b}\right)$, the and total cornea $\left(\mathrm{Z}_{3}{ }^{1}, \mathrm{Z}_{3}{ }^{-1}\right.$, and $\left.\mathrm{Z}_{4}{ }^{0}\right)$ within the $6-\mathrm{mm}$ diameter range centered on the corneal vertex. Only cases where the quality parameters of the examination were shown as "OK" were selected, which indicated the repeatability and reproducibility of the measurements that could be reproduced for a clinical diagnosis. The abovementioned inspections were performed by the same skilled technician.

\section{Statistical analysis}

We utilized the software program SPSS 22.0 (IBM, Chicago, IL, USA) to conduct the statistical analysis. Continuous variables were expressed as mean $\pm S D$, and discontinuous variables were expressed as a percentage (\%). For multiple comparisons, each value was compared by one-way ANOVA following Dunnett's test when each datum conformed to normal distribution, while the nonnormally-distributed continuous data were compared using non-parametric tests. The correlation between the corneal HOAs $\left(\mathrm{Z}_{3}{ }^{1}, \mathrm{Z}_{3}{ }^{-1}\right.$, and $\left.\mathrm{Z}_{4}{ }^{0}\right)$ on the anterior corneal surfaces, posterior corneal surfaces, total cornea and the eye parameter (AL, anterior and posterior corneal surface curvature) were analyzed utilizing a Pearson correlation analysis. A value of $p<0.05$ was considered statistically significant, and $\mathrm{p}$ was the conducted Bonferroni correction $(\mathrm{P} / \mathrm{N})$.

\section{Results}

\section{Patient characteristics}

A total of 183 patients (183 right eyes) were included in this study. The patients' age ranged from 8 to 18 years, and the average age was $11.8 \pm 2.4$ years. Among the 183 participants, there were 75 males (41\%) and 108 females (59\%). The specific baseline characteristics are shown in Table 1.

The correlations between corneal HOAs (coma aberration, $\mathrm{SA}$ ) and ocular parameter (AL, astigmatism, and corneal curvature)

The mean \pm SD and distribution range of HOAs are shown in Table 2. Figure 1 shows the HOAs of the anterior and posterior corneal surface and the total cornea at $6 \mathrm{~mm}$. 
Table 1 Characteristics of the Participants

\begin{tabular}{lll}
\hline Parameter & Mean \pm SD & Range \\
\hline Age (years) & $11.8 \pm 2.4$ & $8 \sim 18$ \\
SE (D) & $-3.47 \pm 0.09$ & $-1.00 \sim-6.00$ \\
AL (mm) & $24.94 \pm 0.88$ & $23.06 \sim 27.52$ \\
$K_{1} f(D)$ & $42.56 \pm 0.07$ & $39.20 \sim 48.10$ \\
$K_{2} f(D)$ & $43.73 \pm 0.08$ & $39.80 \sim 49.50$ \\
$K_{1} b(D)$ & $-6.15 \pm 0.01$ & $-5.60 \sim-6.90$ \\
$K_{2} b(D)$ & $-6.51 \pm 0.01$ & $-5.90 \sim-7.80$ \\
\hline
\end{tabular}

Note: $S E$ Equivalent spherical, $A L$ Axial length, $K_{1} f$ the $K_{1}$ value of the anterior corneal curvature, $K_{2} f$ the $K_{2}$ value of the anterior corneal curvature, $K_{1} b$ the $K_{1}$ value of the posterior corneal curvature, $K_{2} b$ the $K_{2}$ value of the posterior corneal curvature

The results of the correlations between corneal horizontal coma aberration and ocular parameter showed that total corneal horizontal coma $\mathrm{Z}_{3}{ }^{1}$ was significantly correlated with $\mathrm{AL}$ and posterior corneal astigmatism $\left(\mathrm{K}_{2} \mathrm{~b}\right.$ $\left.\mathrm{K}_{1} \mathrm{~b}\right)(r=0.171,0.154, p=0.020,0.038)$. Anterior corneal horizontal coma $\mathrm{Z}_{3}{ }^{1} \mathrm{f}$ was also significantly correlated with AL $(r=0.176, p=0.017)$. Posterior corneal horizontal coma $\mathrm{Z}_{3}{ }^{1} \mathrm{~b}$ was significantly correlated with $\mathrm{K}_{2} \mathrm{~b}\left(\mathrm{~K}_{2} \mathrm{~b}-\right.$ $\left.\mathrm{K}_{1} \mathrm{~b}\right)(r=-0.145,0.188, p=0.050,0.011)$ (Table 3, Fig. 2).

The results of the correlations between corneal vertical coma aberration and ocular parameter showed that total corneal vertical coma $\mathrm{Z}_{3}{ }^{-1}$ was significantly correlated with $\mathrm{K}_{1} \mathrm{~b}$ and anterior corneal astigmatism $\left(\mathrm{K}_{2} \mathrm{f}-\mathrm{K}_{1} \mathrm{f}\right)$ $(\mathrm{r}=-0.151,0.163, p=0.041,0.027)$. Anterior corneal vertical coma $\mathrm{Z}_{3}^{-1} \mathrm{f}$ was significantly correlated with $\mathrm{K}_{1} \mathrm{~b}$ and astigmatism $(r=-0.167,0.168, p=0.024,0.023)$. Posterior corneal vertical coma $\mathrm{Z}_{3}{ }^{-}{ }^{1} \mathrm{~b}$ was significantly correlated with posterior corneal astigmatism $\left(\mathrm{K}_{2} \mathrm{~b}-\right.$ $\left.\mathrm{K}_{1} \mathrm{~b}\right)(r=0.158, p=0.032)$ (Table 4, Fig. 3).

Table 2 Mean \pm SD of corneal spherical aberration and coma in 183 eyes

\begin{tabular}{lll}
\hline & Mean \pm SD & Range \\
\hline$Z_{3}{ }^{1} f$ & $-0.0218 \pm 0.0071$ & $-0.43 \sim 0.47$ \\
$Z_{3}{ }^{1 b}$ & $0.0089 \pm 0.0014$ & $-0.06 \sim 0.17$ \\
$Z_{3}{ }^{1}$ & $-0.0142 \pm 0.0082$ & $-0.41 \sim 0.91$ \\
$Z_{3}{ }^{-1} f$ & $-0.0109 \pm 0.0082$ & $-0.38 \sim 0.63$ \\
$Z_{3}{ }^{-1} b$ & $0.0093 \pm 0.0021$ & $-0.21 \sim 0.12$ \\
$Z_{3}{ }^{1}$ & $-0.0019 \pm 0.0083$ & $-0.49 \sim 0.07$ \\
$Z_{4}{ }^{0} f$ & $0.2281 \pm 0.0042$ & $-0.21 \sim 0.46$ \\
$Z_{4}{ }^{0} b$ & $-0.1485 \pm 0.0017$ & $-0.28 \sim 0.18$ \\
$Z_{4}{ }^{0}$ & $0.1843 \pm 0.0044$ & $-0.10 \sim 0.45$ \\
\hline
\end{tabular}

Note: $Z_{3}{ }^{1} f$, horizontal coma aberration of the anterior corneal surface; $Z_{3}{ }^{1} b$, horizontal coma aberration of the posterior corneal surface; $Z_{3}{ }^{1}$, horizontal coma aberration of the total cornea; $Z_{3}^{-1} f$, vertical coma aberration of the anterior corneal surface; $Z_{3}{ }^{-1} b$, vertical coma aberration of the posterior corneal surface; $Z_{3}{ }^{-1}$, vertical coma aberration of the total cornea; $Z_{4}{ }^{0} f$ spherical aberration of the anterior corneal surface; $Z_{4}{ }^{\circ}$, spherical aberration of the posterior corneal surface; $Z_{4}{ }^{0}$, spherical aberration of the total cornea; Mean $\pm S D$, Mean \pm Standard Deviation $(\mu \mathrm{m})$; Range, $\min$ to $\max (\mu \mathrm{m})$
The results of the correlations between corneal SA and ocular parameters showed that total corneal SA $\mathrm{Z}_{4}{ }^{0}$ was significantly correlated with anterior and posterior corneal curvature $\left(\mathrm{K}_{1} \mathrm{f}, \mathrm{K}_{2} \mathrm{f}, \mathrm{K}_{1} \mathrm{~b}, \mathrm{~K}_{2} \mathrm{~b}\right)(r=0.234,0.246$, $-0.308,-0.284, p<0.05)$. Anterior corneal SA $\mathrm{Z}_{4}{ }^{0} \mathrm{f}$ was significantly correlated with anterior and posterior corneal curvature $\left(\mathrm{K}_{1} \mathrm{f}, \mathrm{K}_{2} \mathrm{f}, \mathrm{K}_{1} \mathrm{~b}, \mathrm{~K}_{2} \mathrm{~b}\right)(r=0.260,0.249$, $0.331,-0.242, p<0.05)$. Posterior corneal $\mathrm{SA} \mathrm{Z}_{4}{ }^{0} \mathrm{~b}$ was significantly correlated with anterior and posterior corneal curvature $\left(K_{1} f, K_{2} f, K_{1} b, K_{2} b\right), A L$, and posterior corneal astigmatism $\left(\mathrm{K}_{2} \mathrm{~b}-\mathrm{K}_{1} \mathrm{~b}\right) \quad(\mathrm{r}=-0.521,-0.460$, 0.464, 0.297, 0.344, 0.180, $\mathrm{p}<0.05$ ) (Table 5, Fig. 4).

\section{The correlations between corneal HOAs and age}

Posterior corneal horizontal coma $\mathrm{Z}_{3}{ }^{1} \mathrm{~b}$, total corneal SA $\mathrm{Z}_{4}{ }^{0}$ and anterior corneal SA $\mathrm{Z}_{4}{ }^{0} \mathrm{f}$ were significantly correlated with age $(r=0.272,0.199,0.191, p<0.05)$ (Table 6).

\section{Discussion}

The outcomes of this study showed that total corneal $\mathrm{Z}_{3}{ }^{1}$ was statistically correlated with posterior corneal astigmatism $\left(K_{2} b-K_{1} b\right)$, and that total corneal $Z_{3}{ }^{1}$ was correlated with anterior corneal astigmatism $\left(\mathrm{K}_{2} \mathrm{f}-\mathrm{K}_{1} \mathrm{f}\right)$. Anterior, posterior, and total corneal $\mathrm{Z}_{4}{ }^{0}$ were correlated with anterior and posterior corneal curvature $\left(K_{1} f, K_{2} f, K_{1} b, K_{2} b\right)$. Posterior corneal $\mathrm{Z}_{4}{ }^{0} \mathrm{~b}$ was also significantly correlated with $\mathrm{AL}$.

To the best of our knowledge, there are few studies on the characteristics of corneal HOAs (the anterior surface, posterior surface and total cornea) in adolescents with mild to moderate myopic eyes. Furthermore, the potential relationship between the ocular parameters (AL and anterior and posterior curvature of the cornea) and corneal HOA was examined, which may provide a reference and direction for an individualized approach for the prevention and control of myopia. Further studies are needed to investigate the change in the aberrations in adolescents with myopia.

In this study, we analyzed the characteristics of corneal HOAs in adolescents with mild to moderate myopic eyes. Previously, SA had been considered as an important factor affecting the quality of vision in HOAs [12, 13]. In our study, however, we observed significantly higher SA of the anterior corneal surface than of the total cornea, which suggests that the posterior corneal surface plays a compensatory role in the balance of corneal aberrations in adolescents with mild to moderate myopic eyes. This result was similar to that of Wu et al. [14], who found that the anterior corneal aberrations are similar to the total corneal aberrations, and that the total corneal aberrations are mainly determined by the anterior surface in adults. However, Sicam et al. [15] reported that the posterior corneal surface had a significant effect on the SA of the cornea in adults. Unlike previous studies, our research focused on the corneal aberration of adolescents with mild to moderate myopic eyes. The higher levels of negative SA would produce 


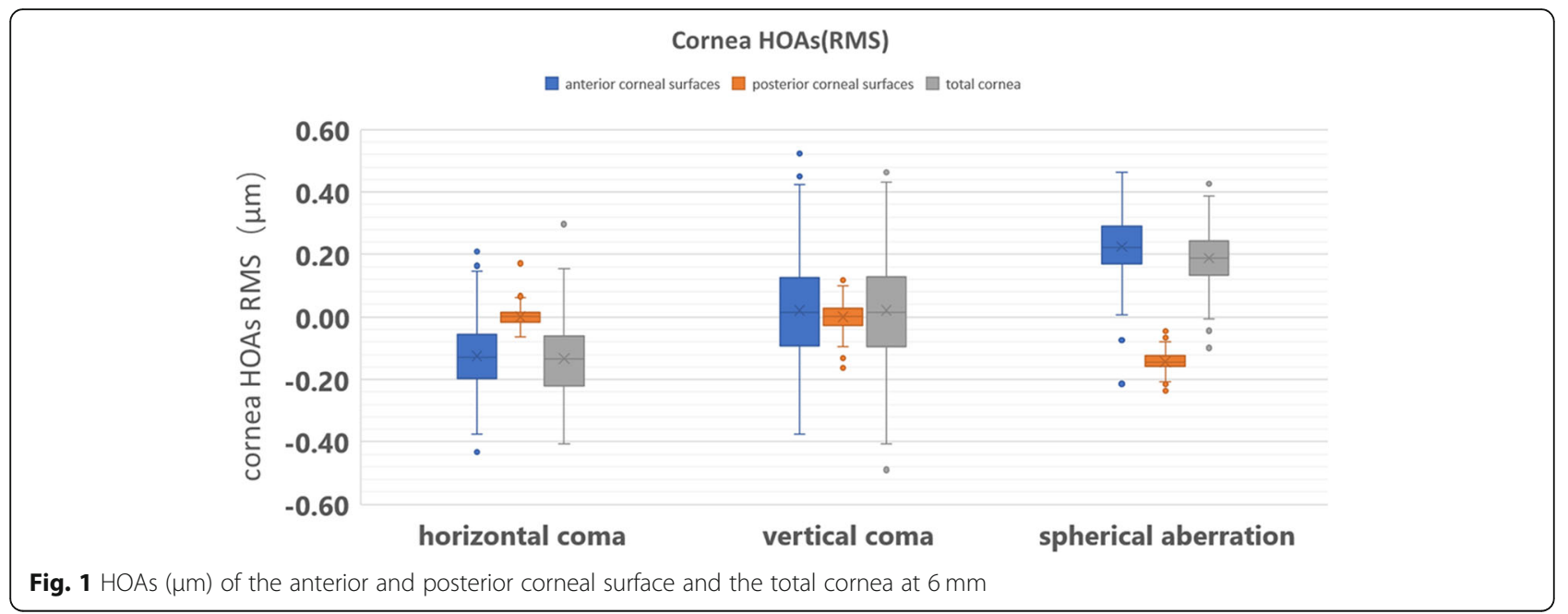

relative peripheral hyperopic defocus and provided an optical cue for myopia progression [16]. Positive SA was associated with less myopic shift [12], and the coma aberrations found in our study were similar to those found in previous studies [12, 14]. The corneal change induced by the eyelid pressure on the superior side can influence the vertical coma [17].

In this study, the relationship between $\mathrm{AL}$ and corneal curvature with corneal SA was analyzed. Anterior, posterior, and total corneal SA were correlated with corneal curvature of the anterior and posterior corneal surface. Since the cornea is flat, the anterior and total corneal SA tend to become less positive or more negative, and the posterior corneal surface SA tends to become less negative. Thus, corneal curvature plays an important role in improving visual quality. The curvature radius of the anterior and posterior surface of the normal cornea from the vertex to the periphery is not the same, there are dissimilarities in its variation, and it has an aspheric surface.

Table 3 The correlation analysis results of corneal horizontal coma aberration with ocular parameter

\begin{tabular}{|c|c|c|c|c|c|c|}
\hline \multirow{2}{*}{$\begin{array}{l}\text { Ocular } \\
\text { parameter }\end{array}$} & \multicolumn{2}{|l|}{$Z_{3}{ }^{1} f$} & \multicolumn{2}{|l|}{$z_{3}{ }^{1} b$} & \multicolumn{2}{|l|}{$\mathrm{Z}_{3}{ }^{1}$} \\
\hline & $r$ & $P$ & $r$ & $P$ & $r$ & $P$ \\
\hline$K_{1} f$ & -0.059 & 0.427 & 0.085 & 0.252 & -0.040 & 0.606 \\
\hline$K_{2} f$ & -0.064 & 0.390 & 0.094 & 0.207 & -0.043 & 0.562 \\
\hline $\mathrm{K}_{1} \mathrm{~b}$ & 0.034 & 0.644 & -0.028 & 0.709 & 0.033 & 0.655 \\
\hline$K_{2} b$ & -0.041 & 0.584 & -0.134 & 0.070 & -0.065 & 0.385 \\
\hline$A L$ & 0.176 & 0.018 & -0.003 & 0.973 & 0.169 & 0.022 \\
\hline astigmatism & 0.019 & 0.802 & 0.085 & 0.254 & 0.042 & 0.574 \\
\hline$K_{2} f-K_{1} f$ & -0.028 & 0.709 & 0.037 & 0.621 & -0.022 & 0.765 \\
\hline$K_{2} b-K_{1} b$ & 0.117 & 0.114 & 0.182 & 0.013 & 0.155 & 0.036 \\
\hline
\end{tabular}

Note: $A L$ Axial length, $K_{1} f$ the $K_{1}$ value of the anterior corneal curvature, $K_{2} f$ the $\mathrm{K}_{2}$ value of the anterior corneal curvature, $K_{1} b$ the $\mathrm{K}_{1}$ value of the posterior corneal curvature, $K_{2} b$ the $\mathrm{K}_{2}$ value of the posterior corneal curvature Pearson correlation analysis was used
Although there was no statistically significant correlation between total corneal SA and ocular AL $(r=-0.106, p=$ $0.154)$, posterior corneal SA was significantly positively correlated with ocular AL $(r=0.344, p<0.001)$, which means that as AL increased, the posterior corneal SA tended to become less negative. In a study of adults, Shimozono et al. [18] found that AL of the eye was significantly negatively correlated with corneal SA $(r=-0.135$, $-0.201, p<0.05)$. Furthermore, Nambe et al. [19] and Hidaka et al. [20] confirmed the relationship between age and HOAs. As the patients' age increases, some HOAs will vary and the AL in adolescent patients will grow, and therefore the relation between ocular AL and corneal SA may vary. The posterior corneal surface compensates for the SA of most anterior corneal surfaces, which reduces the total corneal SA. As the ocular AL grows, the compensatory effect may be changed.

Finally, we analyzed the relation between the corneal coma and the ocular parameter. Posterior and total corneal horizontal coma and posterior corneal vertical coma were correlated with posterior corneal astigmatism $\left(\mathrm{K}_{2} \mathrm{~b}-\mathrm{K}_{1} \mathrm{~b}\right)$ $(p<0.05)$. As the posterior corneal astigmatism $\left(\mathrm{K}_{2} \mathrm{~b}-\mathrm{K}_{1} \mathrm{~b}\right)$ increased, the posterior total corneal horizontal coma and posterior corneal vertical coma tended to become more positive or less negative. Total corneal vertical coma was significantly correlated with anterior corneal astigmatism $\left(\mathrm{K}_{2} \mathrm{f}-\mathrm{K}_{1} \mathrm{f}\right)(p<0.05)$. As the anterior corneal astigmatism $\left(\mathrm{K}_{2} \mathrm{f}-\mathrm{K}_{1} \mathrm{f}\right)$ increased, the posterior and total corneal vertical coma tended to become more positive or less negative. Anterior vertical coma was positively correlated with total astigmatism. As total astigmatism increased, the anterior corneal vertical coma tended to become more positive. Koch et al. [21] reported that neglecting astigmatism on the posterior surface of the cornea in adults would affect the evaluation of astigmatism on the whole cornea. The posterior surface of the cornea has important optical significance; it may play an important role in optical compensation and 
A

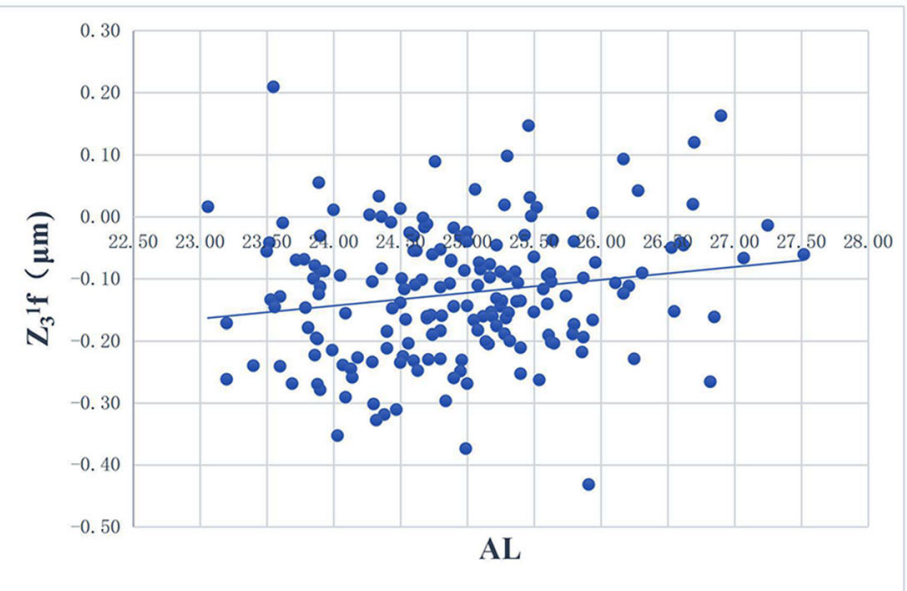

$\mathrm{B}$

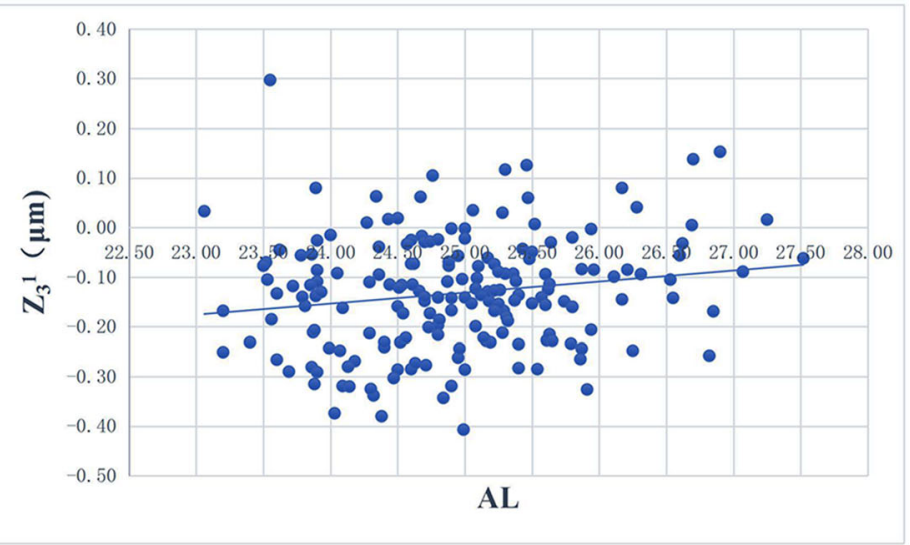

$\mathrm{C}$

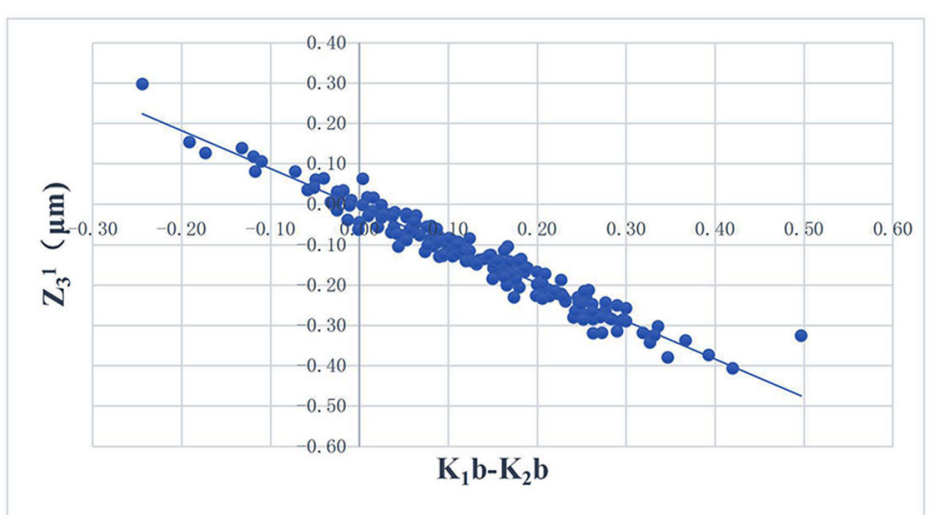

Fig. 2 The results of the analysis of the correlation between corneal horizontal coma aberration and ocular parameter. a: Scatter diagram of the correlation between horizontal coma of the anterior corneal surface and ocular axis length. $\mathbf{b}$ : Scatter diagram of the correlation between horizontal coma of the total cornea and ocular axis length. $\mathbf{c}$ : Scatter diagram of the correlation between horizontal coma of the total cornea and $\mathrm{K}_{1} \mathrm{~b}-\mathrm{K}_{2} \mathrm{~b}$

optimization of visual quality. However, this theory needs to be explored further in future studies.

In this study, some HOAs were significantly correlated with age, including posterior corneal horizontal coma $\mathrm{Z}_{3}{ }^{1} \mathrm{~b}$, total corneal SA $\mathrm{Z}_{4}{ }^{0}$, and anterior corneal SA $\mathrm{Z}_{4}{ }^{0} \mathrm{f}$. In a previous study, Wang et al. [22] showed that aberration changes with age in adults, but this needs to be verified in studies with longer follow-up durations. There was no significant correlation between corneal HOAs and diopter of myopia, which may be different to that found in adults. 
Table 4 The correlation analysis results of corneal vertical coma aberration with ocular parameter

\begin{tabular}{|c|c|c|c|c|c|c|}
\hline \multirow{2}{*}{$\begin{array}{l}\text { Ocular } \\
\text { parameter }\end{array}$} & \multicolumn{2}{|l|}{$Z_{3}^{-1} f$} & \multicolumn{2}{|l|}{$Z_{3}^{-1} b$} & \multicolumn{2}{|l|}{$Z_{3}^{-1}$} \\
\hline & $r$ & $P$ & $\bar{r}$ & $P$ & $r$ & $P$ \\
\hline$K_{1} f$ & 0.081 & 0.275 & -0.109 & 0.144 & 0.048 & 0.520 \\
\hline$K_{2} f$ & 0.124 & 0.095 & -0.103 & 0.164 & 0.106 & 0.153 \\
\hline $\mathrm{K}_{1} \mathrm{~b}$ & -0.168 & 0.023 & 0.104 & 0.161 & -0.151 & 0.042 \\
\hline $\mathrm{K}_{2} \mathrm{~b}$ & -0.119 & 0.108 & -0.004 & 0.955 & -0.127 & 0.087 \\
\hline $\mathrm{AL}$ & 0.016 & 0.835 & 0.017 & 0.816 & 0.077 & 0.302 \\
\hline astigmatism & 0.143 & 0.054 & 0.042 & 0.576 & 0.170 & 0.022 \\
\hline$K_{2} f-K_{1} f$ & 0.132 & 0.075 & -0.014 & 0.854 & 0.165 & 0.026 \\
\hline$K_{2} b-K_{1} b$ & -0.046 & 0.538 & 0.158 & 0.033 & -0.008 & 0.911 \\
\hline
\end{tabular}

Note: $A L$ Axial length, $K_{1} f$ the $K_{1}$ value of the anterior corneal curvature, $K_{2} f$ the $\mathrm{K}_{2}$ value of the anterior corneal curvature, $K_{1} b$ the $\mathrm{K}_{1}$ value of the posterior corneal curvature, $K_{2} b$ the $\mathrm{K}_{2}$ value of the posterior corneal curvature Pearson correlation analysis was used
Table 5 The correlation analysis results of corneal spherical aberration with ocular parameter

\begin{tabular}{|c|c|c|c|c|c|c|}
\hline \multirow{2}{*}{$\begin{array}{l}\text { Ocular } \\
\text { parameter }\end{array}$} & \multicolumn{2}{|l|}{$Z_{4}{ }^{0} \mathrm{f}$} & \multicolumn{2}{|l|}{$\mathrm{Z}_{4}{ }^{0} \mathrm{~b}$} & \multicolumn{2}{|l|}{$\mathrm{Z}_{4}{ }^{0}$} \\
\hline & $\bar{r}$ & $P$ & $\bar{r}$ & $P$ & $\bar{r}$ & $P$ \\
\hline$\overline{K_{1} f}$ & 0.262 & $<0.001$ & -0.514 & $<0.001$ & 0.234 & 0.001 \\
\hline$K_{2} f$ & 0.251 & 0.001 & -0.452 & $<0.001$ & 0.247 & 0.001 \\
\hline $\mathrm{K}_{1} \mathrm{~b}$ & -0.332 & $<0.001$ & 0.456 & $<0.001$ & -0.309 & $<0.001$ \\
\hline $\mathrm{K}_{2} \mathrm{~b}$ & -0.245 & 0.001 & 0.289 & $<0.001$ & -0.286 & $<0.001$ \\
\hline$A L$ & -0.116 & 0.117 & 0.335 & $<0.001$ & -0.108 & 0.146 \\
\hline astigmatism & 0.121 & 0.104 & -0.086 & 0.244 & 0.107 & 0.149 \\
\hline$K_{2} f-K_{1} f$ & 0.038 & 0.611 & 0.030 & 0.684 & 0.094 & 0.204 \\
\hline$K_{2} b-K_{1} b$ & -0.076 & 0.309 & 0.182 & 0.014 & 0.027 & 0.717 \\
\hline
\end{tabular}

Note: $A L$ Axial length, $K_{1} f$ the $K_{1}$ value of the anterior corneal curvature, $K_{2} f$ the $\mathrm{K}_{2}$ value of the anterior corneal curvature, $K_{1} b$ the $\mathrm{K}_{1}$ value of the posterior corneal curvature, $K_{2} b$ the $K_{2}$ value of the posterior corneal curvature Pearson correlation analysis was used

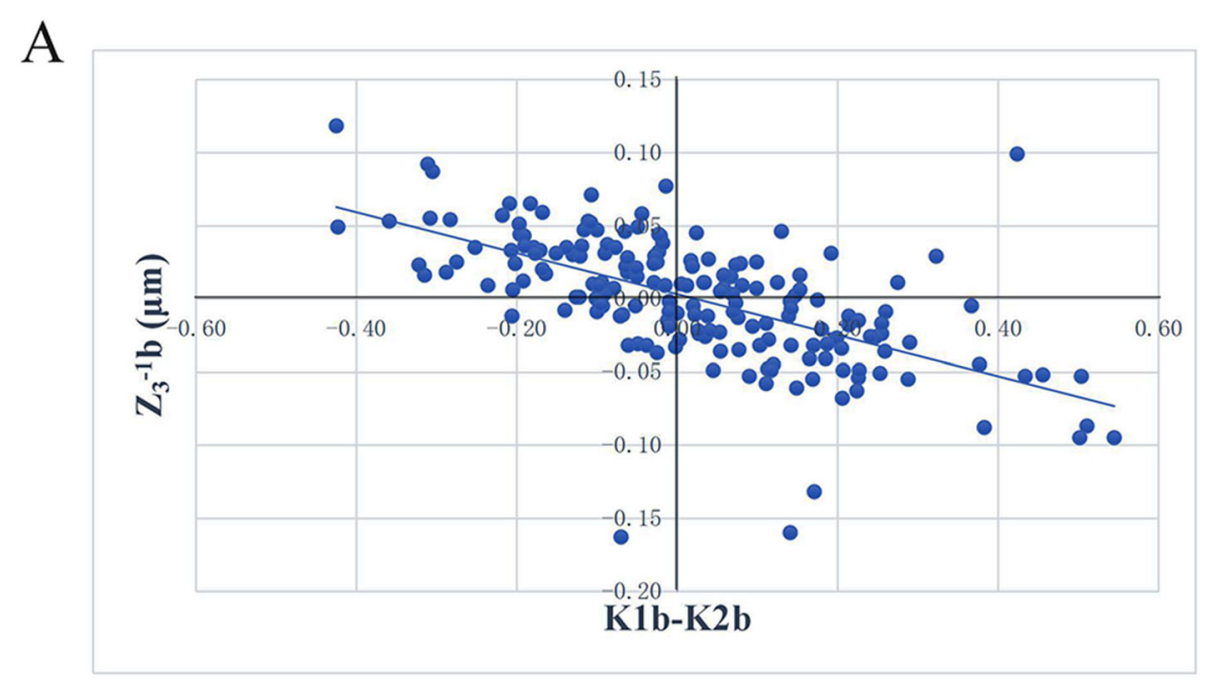

B

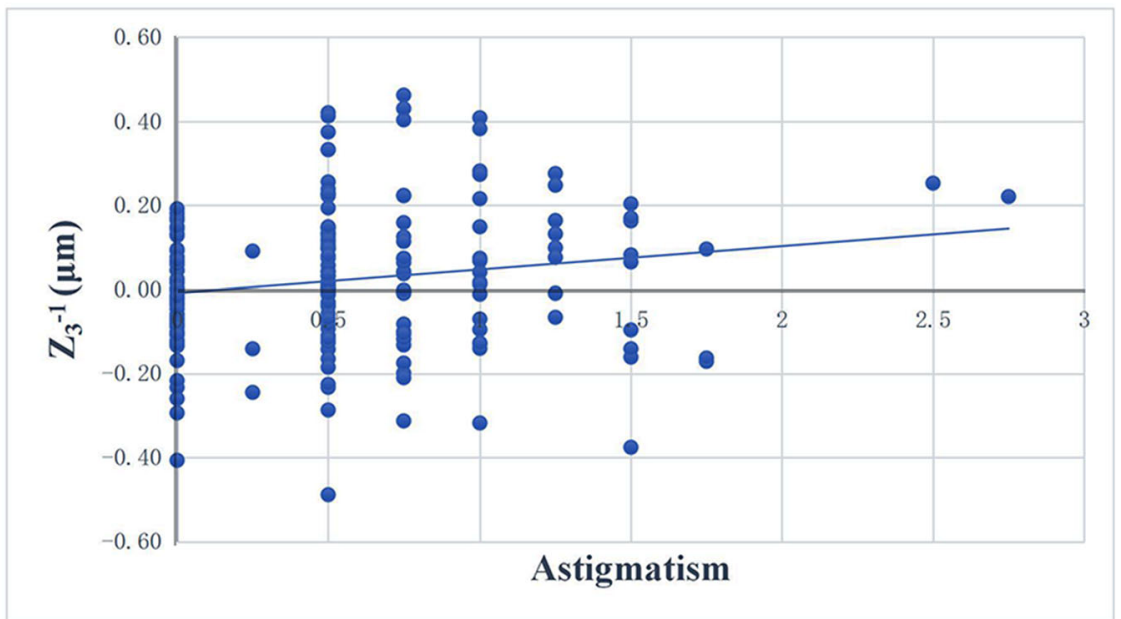

Fig. 3 The results of the analysis of the correlation between corneal vertical coma aberration and ocular parameter. a: Scatter diagram of the correlation between vertical coma of the posterior corneal surface and $K_{1} b-K_{2} b$. $\mathbf{b}$ : Scatter diagram of the correlation between vertical coma of the total cornea and astigmatism 

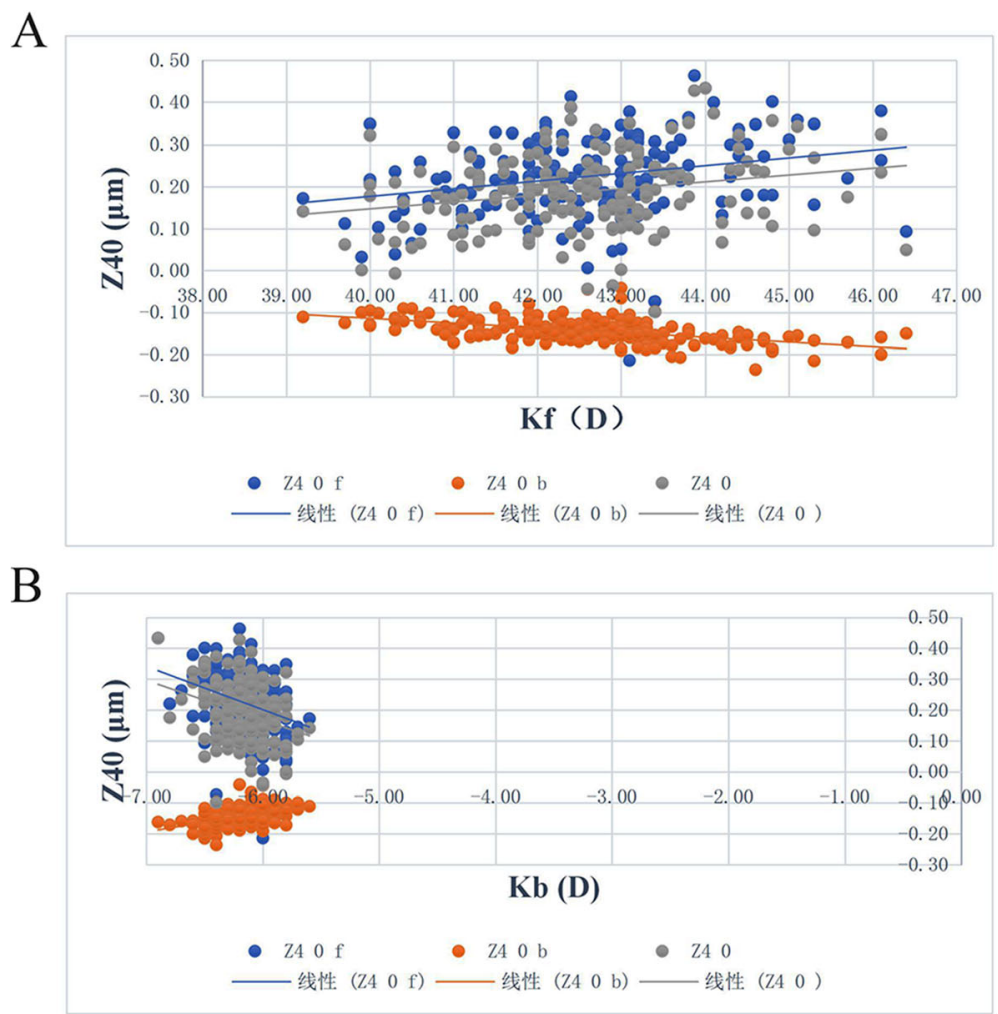

$\mathrm{C}$

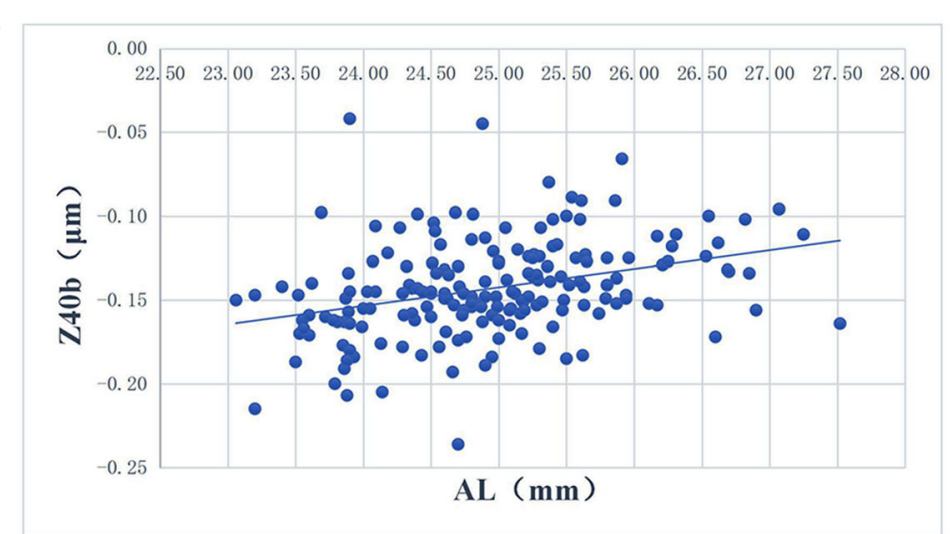

Fig. 4 The results of the analysis of the correlation between corneal spherical aberration and ocular parameter. a: Scatter diagram of the correlation between spherical aberration of the anterior and posterior corneal surface and total cornea with anterior cornea curvature Kf. b: Scatter diagram of the correlation between spherical aberration of the anterior and posterior corneal surface and total cornea with posterior cornea curvature Kb. c: Scatter diagram of the correlation between spherical aberration of the posterior corneal surface and ocular axis length

There is some controversy regarding the relationship between human eye HOAs and myopia diopter. Some studies $[23,24]$ showed more positive HOAs in higher diopter myopia, whereas other studies $[25,26]$ showed less positive HOAs in higher diopter myopia. Moreover, other research studies $[8,25]$ showed no relationship between HOAs and myopia diopter. Our study focused on cornea HOAs and mild to moderate myopic eyes in adolescents. HOAs reflected the precision of the human eye optical system. HOAs have no obvious correlation with diopter of myopia but are directly related to corneal curvature and AL. The magnitude of aberration is mainly due to the combination of optical elements in the ocular itself. However, many aberrations are compensated [27], and therefore not only should the relationship between aberration and diopter be analyzed, but also the corneal curvature and AL should be considered.

However, there were some limitations in this study. First, this study investigated the characteristics of corneal HOAs of the anterior surface, posterior surface and 
Table 6 The correlation analysis results of corneal high order aberration with age, diopter

\begin{tabular}{|c|c|c|c|c|}
\hline \multirow[t]{2}{*}{ Aberration } & \multicolumn{2}{|l|}{ Age } & \multicolumn{2}{|c|}{ Diopter } \\
\hline & $r$ & $P$ & $r$ & $P$ \\
\hline$\overline{Z_{3}{ }^{1} f}$ & 0.050 & 0.505 & 0.046 & 0.536 \\
\hline$z_{3}{ }^{1} b$ & 0.272 & $<0.001$ & 0.048 & 0.521 \\
\hline$z_{3}{ }^{1}$ & 0.107 & 0.151 & 0.050 & 0.505 \\
\hline$Z_{3}^{-1} f$ & 0.064 & 0.389 & 0.127 & 0.086 \\
\hline$Z_{3}^{-1} b$ & 0.073 & 0.326 & -0.027 & 0.719 \\
\hline$Z_{3}^{-1}$ & 0.103 & 0.167 & 0.188 & 0.011 \\
\hline $\mathrm{Z}_{4}{ }^{0} \mathrm{f}$ & 0.199 & 0.007 & 0.155 & 0.036 \\
\hline $\mathrm{z}_{4}{ }^{\circ} \mathrm{b}$ & -0.032 & 0.666 & 0.047 & 0.529 \\
\hline$Z_{4}{ }^{0}$ & 0.191 & 0.010 & 0.136 & 0.067 \\
\hline
\end{tabular}

Note: $Z_{3}{ }^{1} f$, horizontal coma aberration of the anterior corneal surface; $Z_{3}{ }^{1} b$, horizontal coma aberration of the posterior corneal surface; $Z_{3}{ }^{1}$, horizontal coma aberration of the total cornea; $Z_{3}^{-1} f$, vertical coma aberration of the anterior corneal surface; $Z_{3}{ }^{-1} b$, vertical coma aberration of the posterior corneal surface; $Z_{3}{ }^{-1}$, vertical coma aberration of the total cornea; $Z_{4}{ }^{0} f$, spherical aberration of the anterior corneal surface; $Z_{4}{ }^{0} b$, spherical aberration of the posterior corneal surface; $Z_{4}{ }^{0}$, spherical aberration of the total cornea Pearson correlation analysis was used

total cornea in adolescents with mild to moderate myopic eyes. The characteristics of corneal HOAs of the anterior surface, posterior surface and total cornea in other populations are unknown and should be studied further in the future. Second, this study was only a single-center trial and the sample size was limited. A multiple-center trial with a large sample size is still needed to explore in the future.

\section{Conclusion}

In adolescents with mild to moderate myopic eyes, the posterior corneal surface shape plays a compensatory role in the balance of corneal aberrations, and the posterior corneal SA tended to become less negative as the axial length increased. The corneal coma also plays a compensatory role in posterior corneal surface astigmatism, which was valuable for the treatment for improving visual quality. This conclusion still needs to be verified.

\section{Abbreviations}

HOAs: Higher-order aberrations; AL: Axial length; SA: Spherical aberration

\section{Authors' contributions}

$X Z, J H M$ and $X X$ conceived the idea and conceptualized the study and wrote the manuscript. LG collected and analysed the data. All authors read and approved the final draft.

\section{Funding}

This work was supported in data analysis by National Natural Science Foundation of China Grants (No.31701238), Key Research and Development Project of Hebei Provience, China, (No.182777105D) and Key Project Plan of Medical Science Research in Hebei Province, China (No.20180706).

\section{Availability of data and materials}

The datasets generated and/or analysed during the current study are not publicly available due to the lack of an online platform but are available from the corresponding author on reasonable request.

\section{Ethics approval and consent to participate}

This research adhered to the principles provided in the Declaration of Helsinki and was approved by the Institutional Review Board of Clinical College of Ophthalmology in the Tianjin Medical University. Written informed consent was obtained from all patients parents or guardians.

\section{Consent for publication}

Not applicable.

\section{Competing interests}

The authors declare that they have no competing interests.

\section{Author details}

${ }^{1}$ Baoding Yinghua Eye Hospital, Baoding 071000, China. ²Department of endocrinology, Affiliated Hospital of Hebei University, Baoding 071000, China.

${ }^{3}$ Central Laboratory, Affiliated Hospital of Hebei University, No 212.

Yuhuadong Road, Lianchi District, Baoding 071000, China. ${ }^{4}$ Department of mathematics, Hebei Agricultural University, Baoding 071000, China.

Received: 27 December 2019 Accepted: 9 November 2020

Published online: 26 November 2020

\section{References}

1. Ding BY, Shih YF, Lin LLK, Hsiao CK, Wang IJ. Myopia among schoolchildren in East Asia and Singapore. Surv Ophthalmol. 2017:62(5):677-97. https://doi. org/10.1016/j.survophthal.2017.03.006.

2. Rudnicka AR, Kapetanakis W, Wathern AK, Logan NS, Gilmartin B, Whincup $\mathrm{PH}$, et al. Global variations and time trends in the prevalence of childhood myopia, a systematic review and quantitative meta-analysis: implications for aetiology and early prevention. Br J Ophthalmol. 2016;100(7):882-90. https:// doi.org/10.1136/bjophthalmol-2015-307724.

3. Yamaguchi T, Shimizu E, Yagi-Yaguchi Y, Tomida D, Satake Y, Shimazaki J. A novel entity of corneal diseases with irregular posterior corneal surface. Cornea. 2017;36:S53-9. https://doi.org/10.1097//CO.0000000000001388.

4. Chan TCY, Wong ES, Chan JCK, Wang Y, Yu M, Maeda N, et al. Corneal backward scattering and higher-order aberrations in children with vernal keratoconjunctivitis and normal topography. Acta Ophthalmol. 2017;96(3): e327-33. https://doi.org/10.1111/aos.13566.

5. Jiang $Y$, Wang $Y$, Zhang J, Chen $X$, Li L, Zhao H, et al. Dynamic changes in higher-order aberrations after correction of lower-order aberrations with adaptive optics in myopic and emmetropic eyes. Appl Opt. 2018;57(3):51420. https://doi.org/10.1364/AO.57.000514.

6. Wang J, Ren Y, Liang K, Jiang Z, Tao L. Changes of corneal high-order aberrations after femtosecond laser-assisted in situ keratomileusis. Medicine. 2018;97(18):e0618. https://doi.org/10.1097/MD.0000000000010618.

7. Kirwan C, O'Keefe M, Soeldner H. Higher-order aberrations in children. Am J Ophthalmol. 2006;141:67-70.

8. Cheng X, Bradley A, Hong X, Thibos LN. Relationship between refractive error and monochromatic aberrations of the eye. Optom Vis Sci. 2003;80(1): 43-9. https://doi.org/10.1097/00006324-200301000-00007.

9. Hiraoka T, Kakita T, Okamoto F, Oshika T. Influence of ocular wavefront aberrations on axial length elongation in myopic children treated with overnight orthokeratology. Ophthalmology. 2015;122(1):93-100. https://doi. org/10.1016/j.ophtha.2014.07.042

10. Hiraoka T, Kotsuka J, Kakita T, Okamoto F, Oshika T. Relationship between higherorder wavefront aberrations and natural progression of myopia in schoolchildren. Sci Rep. 2017;7:7876. https://doi.org/10.1038/s41598-017-08177-6.

11. Pietila J, Huhtala A, Jaaskelainen M, Jylli J, Makinen P, Unsitalo H. LASIK flap creation with the Ziemer femtosecond laser in 787 consecutive eyes. J Refract Surg. 2010;26(1):7-16. https://doi.org/10.3928/1081597X-20101215-02.

12. Jin $H Y$, Wan $T, Y u X N$, Wu F, Yao K. Corneal higher-order aberrations of the anterior surface, posterior surface, and total cornea after small incision lenticule extraction (SMILE): high myopia versus mild to moderate myopia. BMC Ophthalmol. 2018;18(1):295. https://doi.org/10.1186/s12886-018-0965-1.

13. Superstein R, Boyaner D, Overbury O. Functional complaints, visual acuity, spatial contrast sensitivity, and glare disability in preoperative and 
postoperative cataract patients. J Cataract Refract Surg. 1999;25:575-81. https://doi.org/10.1016/s0886-3350(99)80059-5.

14. Wu W, Wang Y. Corneal higher-order aberrations of the anterior surface, posterior surface, and Total cornea after SMILE, FS-LASIK, and FLEx surgeries. Eye Contact Lens. 2016;42(6):358-65. https://doi.org/10.1097//CL.0000000000000225.

15. Sicam VA, Dubbelman M, van der Heijde RG. Spherical aberration of the anterior and posterior surfaces of the human cornea. J Opt Soc Am A Opt Image Sci Vis. 2006;23(3):544-9. https://doi.org/10.1364/josaa.23.000544.

16. Thibos LN, Bradley A, Liu T, López-Gil N. Spherical aberration and the sign of defocus. Optom Vis Sci. 2013;90(11):1284-91. https://doi.org/10.1097/OPX. 0000000000000040

17. Zhou W, Stojanovic A, Utheim TP. Assessment of refractive astigmatism and simulated therapeutic refractive surgery strategies in coma-like-aberrationsdominant corneal optics. Eye Vis (Lond). 2016;3(1):13. https://doi.org/10. 1186/s40662-016-0044-8 eCollection 2016

18. Shimozono M, Uemura A, Hirami Y, Ishida K, Kurimoto Y. Corneal spherical aberration of eyes with cataract in a Japanese population. J Refract Surg. 2010;26:457-9

19. Namba H, Sugano A, Nishi K, Murakami T, Nishitsuka K, Konta T, et al. Agerelated variations in corneal geometry and their association with astigmatism: the Yamagata study (Funagata). Medicine (Baltimore). 2018; 97(43): 12894

20. Hidaka Y, Yamaguchi T, Saiki M, Dogru M, Tsubota K, Negishi K. Changes in corneal aberrations after cataract surgery. Jpn J Ophthalmol. 2016;60(3):135-41.

21. Koch DD, Ali SF, Weikert MP, Shirayama M, Jenkins R, Wang L. Contribution of posterior corneal astigmatism to total corneal astigmatism. J Cataract Refract Surg. 2012;38:2080-7. https://doi.org/10.1016/j.jcrs.2012.08.036.

22. Wang $Y$, Zhao K, Yang X, He J, Wang W. Higher order aberrations and low contrast vision function in myopic eyes $(-3.00$ to $-6.00 \mathrm{~d}$ ) under mesopic conditions. J Refract Surg. 2011;27:127-34.

23. Jain AK, Malhotra C, Pasari A, Kumar P, Moshirfar M. Outcomes of topography-guided versus wavefront-optimized laser in situ keratomileusis for myopia in virgin eyes. J Cataract Refract Surg. 2016;42(9):1302-11. https://doi.org/10.1016/j.jcrs.2016.06.035.

24. El-Mayah E, Anis M, Salem M, Pinero D, Hosny M. Comparison between Qadjusted LASIK and small-incision Lenticule extraction for correction of myopia and myopic astigmatism. Eye Contact Lens. 2018;44:S426-32. https://doi.org/10.1097/ICL.0000000000000532.

25. Kobashi H, Kamiya K, Hoshi K, Igarashi A, Shimizu K. Wavefront-guided versus non-Wavefront-guided photorefractive keratectomy for myopia: meta-analysis of randomized controlled trials. PLoS One. 2014;9(7):e103605. https://doi.org/10.1371/journal.pone.0103605 eCollection 2014.

26. Li T, Zhou X, Chen Z, Zhou X, Chu R, Hoffman MR. Relationship between ocular wavefront aberrations and refractive error in Chinese school children. Clin Exp Optom. 2012;95(4):399-403. https://doi.org/10.1111/j.1444-0938.2012.00739.x.

27. Li X, Wang Y, Dou R. Aberration compensation between anterior and posterior corneal surfaces after small incision lenticule extraction and femtosecond laser-assisted laser in-situ keratomileusis. Ophthalmic Physiol Opt. 2015;35(5):540-51.

\section{Publisher's Note}

Springer Nature remains neutral with regard to jurisdictional claims in published maps and institutional affiliations.

Ready to submit your research? Choose BMC and benefit from:

- fast, convenient online submission

- thorough peer review by experienced researchers in your field

- rapid publication on acceptance

- support for research data, including large and complex data types

- gold Open Access which fosters wider collaboration and increased citations

- maximum visibility for your research: over $100 \mathrm{M}$ website views per year

At $\mathrm{BMC}$, research is always in progress.

Learn more biomedcentral.com/submissions 